http://doi.org/10.4038/sljm.v26i1.28

KSM ORATION 2017

\title{
COGNITIVE TOXICITY: FROM PESTICIDES TO PHARMACEUTICALS
}

\author{
Tharaka Lagath Dassanayake
}

Professor in Neurophysiology, Faculty of Medicine, University of Peradeniya, Sri Lanka

\begin{abstract}
Impairment of cognitive functions following neurotoxic exposure is collectively termed cognitive toxicity. This oration is based on a series of studies carried out over last 12 years on cognitive toxicity of two groups of substances, viz. organophosphate (OP) pesticides and sedative psychotropic drugs.
\end{abstract}

OP pesticide poisoning is a major clinical and public health problem in South Asia. OPs act as cholinesterase inhibitors, and bring about acute neurological deficits following exposure. Using neurophysiological and neuropsychological techniques, we assess long-term neurocognitive deficits of OPs, a less known yet important adverse effect of OP exposure. The findings hitherto indicate both acute large-dose poisoning and subclinical occupational exposure are associated with long-term cognitive impairment.

In the same way the pesticide use and misuse are common in agricultural communities, use and misuse of sedative psychotropic medications are common in urbanised societies. Sedative drugs, even in therapeutic doses impair driving and underlying cognitive functions, and increase the risk of traffic accidents. When taken in overdose, these drugs have cognitively impairing effects that last beyond clinical recovery from acute poisoning. These patients are more prone to traffic crashes at least up to 4 weeks following exposure, and the cognitive recovery over this period mirrors the crash risk at different post-overdose time points. The above findings raise a number of clinical and medico legal implications in post-discharge management of patients with sedative drug overdose.

As the agricultural communities transform into urban industrialised societies in Sri Lanka, the pattern of poisoning changes from agrochemicals into pharmaceuticals, particularly psychotropic dugs. The two lines of research discussed above highlight how this changing social fabric poses new challenges for the neurophysiologists, neurologists and psychiatrists who study cognition and apply their findings in clinical settings. Our latest work in generating age-, sex- and education-adjusted norms for cognitive tests for Sri Lankans, would set the foundation in interpreting the cognitive test results of clinical populations.

\section{Cognitive Toxicity: From Pesticides to Pharmaceuticals (Oration transcript)}

President of the Kandy Society of Medicine, Dr. Anoma Siribaddana, Chief Guest, Professor Oliver Illeperuma, the Guest of Honour Dr. Upul Wijayawardana, Past Presidents, Council members and members of the Kandy Society of Medicine, distinguished invitees, ladies and gentlemen. First of all let me express my deepest gratitude to the President and the Council of the Kandy Society of Medicine for giving me the opportunity to deliver the prestigious KSM Oration in 2017. 
The American author and biochemist, Isaac Asimov once said, "Your assumptions are your windows on the world. Scrub them off every once in a while, or the light won't come in". I think that sums up what we do as scientists: scrubbing off our assumptions with scientific method. My duty in front of this august gathering then, is to tell how I have been scrubbing off my assumptions opening into the world of neuroscience, and hopefully to show you some light that is coming in.

The title that I have chosen for this oration is 'Cognitive Toxicity: from Pesticides to Pharmaceuticals'. In this talk I will present you the research that I carried out over last 12 years on cognitive toxicity of two different groups of substances, viz. organophosphate pesticides and sedative psychotropic drugs.

\section{What is cognitive toxicity?}

We know that different toxins adversely affect the nervous system and its functions. The toxicity sometimes involves brain, and impairs so called 'higher functions' or cognitive functions, giving rise to the entity collectively termed cognitive toxicity. Cognitive toxicity sometimes leads to overt clinical manifestations such as impaired consciousness, disorientation, delirium or amnesia. These can be readily detected in the acute stage of intoxication. What is less encountered by the clinician, are the delayed effects of acute poisoning and the subclinical effects of long-term exposure to toxins. These effects may include subtle deficits in different cognitive functions including perception, memory, attention and executive functions. These subtle effects - as we see later - are none the less detrimental to the health and wellbeing of the patients.

\section{How do we assess and quantify cognitive functions?}

The structure of the brain per se does not satisfactorily explain its workings. Francisco Mora aptly put this into perspective: 'Time, not space, is the crucial dimension of the mind. Mind is the neural tissue sewn with the threads of time'. The greatest challenge of the neuroscientist is then un-weave these threads. And unravel the workings of the brain in health and disease.

Let me explain how we can combine different techniques to study these time-dominated cognitive functions, using a method that we developed in Peradeniya. The basic behavioural task is pressing a button in response to a visual stimulus. The computer measures the 'visual reaction time', i.e. the time interval between the onset of the visual stimulus and the button-press, which is about $250 \mathrm{~ms}$. This visual reaction consists of sensory (visual afferent) conduction component, a central 'cognitive processing' component and a motor (efferent) conduction component. If we were to study the effect of a substance on cognitive processing time in this task, we will have to first isolate the cognitive processing component, dissecting out the time taken for sensory and motor conduction. We did this by combining the VRT test with neurophysiological techniques. We recorded the visual evoked potentials (VEP) and measured the VEP latency, i.e. the duration of the afferent visual transmission from retina to the visual cortex, which is about $100 \mathrm{~ms}$. Then we stimulated the motor cortex through transcranial magnetic stimulation (TMS) and recorded the motor evoked potential (MEP) latency and measured the duration motor transmission from primary motor cortex to the contracting muscle, which is about $15 \mathrm{~ms}$. By subtracting the VEP latency and MEP latency from visual reaction time we could isolate the 'cognitive processing time' of the visual reaction, which was about $135 \mathrm{~ms}$. We presented this technique initially in local conferences in $2004^{1,2}$, and later used it to study cognitive impairment following organophosphate pesticide poisoning ${ }^{3}$ and cognitive enhancing effects of theanine, a constituent in tea ${ }^{4}$.

In our laboratories at the Faculty of Medicine and the Teaching Hospital Peradeniya, we employ a number of other neurophysiological and neuropsychological techniques to test cognitive functions. I will 
elaborate on these techniques and tests as I take you through my research.

This brings us to the main body of this oration: cognitive toxicity of pesticides and pharmaceuticals.

\section{Cognitive Toxicity of Organophosphate Pesticides}

Pesticides are widely used in agriculture across the globe. Occupational exposure and intoxication mainly occur through inhalation and skin contact. Pesticide sprayers who do not use protective gear are particularly at risk. However, most clinically documented acute poisonings in Sri Lanka are not due to occupational overexposure, but episodes of deliberate ingestion as a means of self harm ${ }^{5}$. Organophosphates (OP) are the most common type of pesticides used by individuals who attempt self-harm ${ }^{6,7}$.

OPs inhibit acetylcholinesterase (AChE), the enzyme which degrades the neurotransmitter acetylcholine (ACh) released by cholinergic nerve endings. Resulting accumulation of ACh leads to acute neuromuscular, autonomic and central nervous system disturbances, collectively named as cholinergic crisis. Classically two other syndromes of organophosphate poisoning have also been described, viz. intermediate syndrome ${ }^{8}$ and delayed polyneuropathy".

In addition to these manifestations, research over last few decades suggests the possibility of OPs affecting cognitive functions ${ }^{10}$. The first reports of cognitive toxicity of organophosphate poisoning dates back to 1960s. They mainly reported symptoms such as poor memory, confusion, anxiety, drowsiness, fatigue, depression and irritability in patients heavily exposed to OP compounds $^{11-14}$. Although these studies were of little help in elucidating the mechanisms of cognitive toxicity, they have, for the first time, highlighted the possibility of development of 'chronic OP-induced neuropsychiatric disorders ${ }^{15}$. After these early studies, research on long-term cognitive toxicity of OP compounds pursued along two lines:

1. Delayed cognitive sequelae of an acute OP poisoning ${ }^{16-19}$.

2. Cognitive manifestations of prolonged exposure to OPs without preceding episodes of acute poisoning. Changes with chronic low-level exposure were studied in many occupational groups including farmers ${ }^{20,21}$, farm-workers ${ }^{22,23}$, sheep-dippers ${ }^{24}$ and termiticide applicators $^{25}$.

However, these studies suffered two major limitations: 1) paucity of objective evidence of cognitive impairment and 2) lack of understanding of neurophysiological underpinnings of potential impairment in $\mathrm{OP}$ exposure.

Potential cognitive toxicity of OPs has drawn attention of not only toxicologists, but also the researchers in neurology, neurophysiology and neuropsychology. I embarked in this area of study in 2004. I was fortunate to have the guidance of a multidisciplinary team in my research on OPs. The team included, Prof. Vajira Weerasinghe my mentor at the time, Prof. Nimal Senanayake and Dr. Lakshman Karalliedde, the two scientists who described the intermediate syndrome, Prof. Indika Gawarammana, Prof. Andrew Dawson, Dr. Udaya Dangahadeniya and Dr. Keerthi Kularatne.

In our first line of studies on OPs, we focused on delayed cognitive effects of acute poisoning. We developed this work under a backdrop of the human studies that I described earlier, and a series of animal experiments. Those studies suggest that acute large-dose exposure to OPs lead to overstimulation of cholinergic circuits of the brain leading to excitotoxicity. The excitotoxicity is characterized by increased oxygen demand, ionic imbalances, cellular oedema, inflammation and cytotoxicity. On long term this is followed by apoptosis, axonal degeneration and neuronal loss in the 
experimental animals ${ }^{10,26}$. If this is the case also in humans, we hypothesized that this brain damage should manifest as objective, physiological markers of brain function of patients with OP poisoning.

First, we explored the effect of OP pesticide poisoning on cognitive processing visual information $^{3,27,28}$. We compared a group of patients who recovered from the cholinergic phase of poisoning (on average, 15 days after poisoning) with an age- and sex-matched control group. The subjects did two types of visual reaction time tasks: one to assess simple stimulus detection and the other visual stimulus discrimination. As I explained under the cognitive assessment techniques, we isolated the cognitive processing component of each task by measuring VEPs and MEPs and subtracting the sensory and motor components, respectively. We found that no significant difference in P100 latency or total motor conduction time between patients and the controls. However, cognitive processing times of both simple visual reactions and recognition visual reactions were prolonged in OP patients ${ }^{3}$. These findings imply that acute organophosphate poisoning may slow higher-order cognitive processing involved in visual stimulus detection and visual stimulus discrimination, even after clinical recovery from the cholinergic phase.

We also investigated the delayed effects of OP poisoning on cognitive processing of auditory information ${ }^{28,29}$. Here we employed event related potential (ERP) techniques to study cognitive toxicity. We know what evoked potentials are: they are the electrical potentials generated by sensory conduction. ERPs are electrical potentials generated by of specific cognitive processes occurring in the brain $^{30}$. ERPs are derived from real-time EEG that we record when a subject performs particular cognitive task. In this technique we expose the subjects to different stimulus paradigms and get them to respond accordingly, therefore experimentally manipulate the cognitive processes occurring in their brains. The test performance of the subjects gives the behavioural data (i.e. accuracy and speed of the cognitive task) while concurrent ERPs give neurophysiological underpinning of that behaviour. In this way, ERP components literally tell us the 'thinking pattern' of our brain circuits up to a millisecond-accuracy.

The ERP experimental paradigm that we used in OP studies is called the 'oddball paradigm'. The subjects are exposed to two different sounds randomly: one presented frequently ( $80 \%$ probability) and the other infrequently ( $20 \%$ probability). They have to ignore the more frequently presented sound and press a button to the infrequent sound. In other words, they will have to pay selective attention to the infrequent sound. ERP components represent different stages of selective attention processes of the brain of the subject.

Of the different ERP components, our primary interest was on a component called P300 which is a neurophysiological index of stimulus classification $^{31,32}$. The peak latency of the P300 component is a measure of stimulus classification speed, and the P300 amplitude is a measure of the amount of neuronal resources allocated to the cognitive task. Medial temporal lobe structures are thought to be among the neural generators of P300 component. Importantly, animal studies have found OPs to damage the same brain region $^{33,34}$. Therefore we hypothesised that OP poisoning would do the same in patients with acute poisoning, which then should manifest as changes in P300 ERP component. More specifically we expected the OP patients to have delayed P300 peak latency and/or reduced P300 amplitude.

In this study we compared our OP patient group with two control groups: age- and sexmatched health controls and patients hospitalised with paracetamol overdose ${ }^{29}$. Again we tested the patients after recovery from the acute stage of poisoning, i.e. on the day of discharge from hospital. The OP group had a significant delay in P300 latency ( $p$ $<0.01)$ compared to both control groups. P300 amplitude also tended to be blunted in the OP group but was not significant. The 
latency delay did not improve in the OP group even at a follow up assessment at 6 months post-exposure.

In a subsequent study, we observed similar impairments in ERPs in vegetable farmers who had chronic occupational exposure to OP pesticides but no history of acute poisoning that required hospitalisation ${ }^{35,36}$. Interestingly this study showed progressing impairments in the latencies of consecutive ERP components in the control OP exposed group, with a significant delay not only in the P300 component but also the earlier stages of attentional processes of the brain.

Given that there is a long-term cognitive impairment in OP poisoning, a clinician would want to know the risk factors of such impairment. Preliminary data from our ongoing work gives some insights into this ${ }^{37}$. The candidate risk factors for cognitive impairment we included were age, sex, hypoxia in the acute stage of poisoning and major psychiatric diagnosis. Of these, hypoxia (as indexed by respiratory arrest or blood oxygen saturation $<90 \%$ ) emerged as a significant risk factor of delayed reaction time and delayed P300 latencies. The possible hypoxic brain damage could be worsened by increased the oxygen demands of the cholinergic circuits of the brain and other cytotoxic mechanisms initiated in the acute stage of poisoning, as documented in animal models ${ }^{26}$.

At this stage, let me summarise the evidence that I presented so far. OP poisoning appears cause to long-term cognitive toxicity that entail impaired processing of visual and auditory information. Our findings combined with animal studies suggest that this could be caused by damage to the neural substrates of selective attention. In the context of acute OP poisoning, our preliminary data suggest that monitoring blood oxygen saturation and prevention of hypoxia in the acute stage of poisoning may help to counteract long term cognitive effects, however this evidence is not conclusive.
What are the possible implications of these impairments to the patients and the farmers? Impaired selective attention reduces the efficiency of day-to-day activities. Particularly, slowed selective attentional deployment would increases the accident risk in time-constrained daily activities such as driving and operating machinery which is increasing being adopted by the agricultural community in Sri Lanka. I will discuss further implications of cognitive toxicity on daily functioning under the next half of my talk. With this let me enter the second topic for today's oration:

\section{Cognitive Toxicity of Sedative Psychotropic Medication and its Implications in Day-to-Day Functioning}

In the same way the pesticide use and misuse are common in agricultural communities, use and misuse of psychotropic medication are common in urbanised societies. During this part of the talk I will focus on psychotropic medications with sedative or central nervous system (CNS) depressant effects. The most widely prescribed sedative psychotropic drugs are benzodiazepines, opioids, sedative antidepressants, atypical antipsychotics ${ }^{38-43}$.

Many outpatients treated with these drugs are expected to carry out day-to-day activities, like their healthy counterparts. With exponential increase in the number of motor vehicles on roads, it is inevitable that many of the patients taking these medications getting behind the wheel. Neurophysiological and neuropsychological experiments show that the CNS-depressant medications impair an array of cognitive functions underlying driving and other everyday activities ${ }^{44-47}$. The cognitive effects include impaired visual attention and reaction time ${ }^{47-51}$, attentional switching ${ }^{52}$, planning ${ }^{53}$ and working memory ${ }^{54}$. In addition benzodiazepines cause anterograde amnesia and increased impulsivity ${ }^{55}$.

I commenced my work in this area by conducting a systematic review on the effects of benzodiazepines, antidepressants and opioids on driving and the risk of traffic $\operatorname{accidents}^{56}$. 
Of different classes of CNS depressant drugs the most profound impairment occurs with benzodiazepines which are prescribed as anxiolytics and hypnotics in outpatient settings. When taken in single or multiple doses during the daytime as anxiolytics, benzodiazepines tend to impair driving somewhat independent of their half-lives. When taken at night time as hypnotics, the accident risk and the possibility of daytime driving impairment tend to be related to their plasma half-lives, with some exceptions. Short-acting benzodiazepine hypnotics and 'z-drugs' cause minimal or no 'morning-after' effects on driving. Our meta-analyses of case-control and cohort studies indicate that benzodiazepines, as a group, are associated with a 60 (for case-control studies: pooled odds ratio [OR] $1.59 ; 95 \% \mathrm{CI} 1.10,2.31)$ to $80 \%$ (for cohort studies: pooled incidence rate ratio: $1.81 ; 95 \% \mathrm{CI} 1.35,2.43)$ increase in the risk of traffic accidents. To contextualise these figures, it is noteworthy that a blood alcohol level of $0.05 \mathrm{~g} / \mathrm{dl}$ (which is the legal limit for driving in most countries) increases accident risk only by $50 \%$. Meta-analysis of case-control studies on accident culpability shows that drivers responsible for traffic accidents are $40 \%$ (pooled OR 1.41; 95\%CI 1.03, 1.94) more likely to be positive for benzodiazepines than those who are not responsible, suggesting that benzodiazepines actually may play a causative role in traffic accidents. This indicates that driving after taking benzodiazepines is as risky as drunk riving. This has led to the problem which can be rather ironically - referred to as 'driving under the influence of prescription medication'.

Deleterious effects of benzodiazepines are potentiated by co-ingestion of other sedative substances. Our meta-analysis showed that the presence of alcohol and benzodiazepines is associated with 7.7-fold (pooled OR 7.69; $95 \% \mathrm{CI} 4.33,13.65)$ increase in the risk of traffic accidents. Evidence from experimental studies supports this assertion. Benzodiazepines also interact with sedative antidepressants to impair driving skills and increase the risk of accidents. Drug information sheets and warning labels should specify this interactive effect on driving, and prescribers should warn patients that the benzodiazepine-alcohol combination may markedly increase the risk of accidents even if the blood alcohol levels are below the legal limit for driving $(0.5-0.8 \mathrm{~g} / \mathrm{dL}$ in most countries).

Limited evidence suggests that tricyclic antidepressants could be associated with an increased traffic accident risk in the elderly. There is no clear distinction between sedative and non-sedative antidepressants and their association with traffic accidents in epidemiological studies, particularly in young patients using antidepressants ${ }^{57-59}$. Presumably, one major source of confounding in patient studies is the condition to which the drugs are prescribed (i.e. depression), which in itself can impair the cognitive functions underlying driving. To begin with, cognitive and psychomotor deficits of depression itself may limit driving capacity of an individual. Because the antidepressants do not bring therapeutic effects immediately after commencement of treatment, depressed patients may show driving impairment during the first 1-2 weeks of treatment, even if their antidepressants are non-sedative. Patients taking sedative antidepressants may be affected more than those on non-sedating antidepressants during this initial stage because of the acute sedative effects of the drugs, as has been observed in healthy volunteers in experimental studies. Continuing treatment beyond 3-4 weeks tends to improve depression, and patients tend to become tolerant to sedative effects of sedating antidepressants. This is supported by limited experimental evidence that showed that young patient groups treated with sedative or non-sedative antidepressants improved their driving skills after a few weeks while untreated patients did not ${ }^{60-62}$.

Few epidemiological studies conducted so far suggest that opioid users could be at greater risk of traffic accidents in the first few weeks of treatment; however, scarce experimental data do not provide conclusive 
evidence on whether opioids impair driving in patients receiving treatment. As with antidepressants, the interactive effect of opioids and underlying conditions such as chronic pain on driving performance is also not clear.

So far I have been presenting the evidence of cognitive toxicity of therapeutic doses of psychotropic medications. Now I will talk about the cognitive effects of CNSdepressant overdose, which is important in the contexts of emergency medicine, clinical toxicology and psychiatry. Psychotropic drug overdose is not a very common form of poisoning in Sri Lanka at present. However, with urbanisation of the Sri Lankan society, we see a gradual change in the pattern of poisonings, with agrochemicals and plant poisons giving way to pharmaceuticals including psychotropic medications.

CNS-depressant drugs are among the most commonly ingested substances in selfpoisoning in the United States ${ }^{63}$, United Kingdom $^{64}$ and Australia ${ }^{65}$. According to the tertiary care clinical toxicology admission statistics in Australia, atypical antipsychotics, benzodiazepines and opioids are the $1^{\text {st }}, 3^{\text {rd }}$ and $7^{\text {th }}$ commonest classes of drugs of overdose, respectively (Hunter Area Toxicology Services Database, unpublished).

Most of the patients hospitalised with CNS depressant overdose are managed in emergency departments or general medical units and less frequently in specialised clinical toxicology departments. The inhospital management primarily consists of supportive care and monitoring for complications. Only a small minority develop complications of overdose such as seizures, respiratory depression or profound hypotension and subsequent hypoxic brain damage. The vast majority of the patients recover from acute toxicity without complications. The decision to discharge from the hospital is made by a physician team based on clinical observations. The neurological assessment of recovery taps only into the domains of orientation (in time, place and person), motor coordination and independence of self-care such as feeding and toileting. No specific tests are carried out to assess recovery of higher cognitive functions that are important in daily activities. It is expected that these functions return to normal as the drug effects wear off, however the time the patients spend in hospitals could be too short for a complete cognitive recovery.

The length-of-hospital-stay statistics, particularly those in the $\mathrm{UK}^{64}$ and Australia ${ }^{65}$ indicate that the majority of the patients with CNS-depressant drug overdose are discharged from hospitals within 24-48 hours after admission. In the centre where I was trained in Australia, the median duration of stay is 13.8 hours, and around two-thirds of the patients are discharged within 24 hours (Hunter Area Toxicology Services Database, unpublished).

Given this background, any residual cognitive and psychomotor impairment at the time of discharge may impact on their daily activities such as driving, operating machinery and other domestic and workplace tasks during the post-discharge period. The aim of our first study was to determine whether patients with CNS-depressant overdose are cognitively impaired at the time they are clinically deemed fit to be discharged from hospital ${ }^{66-68}$.

We focused our assessment on three neurocognitive domains underpinning daily activities of social and professional life viz. a) visual attention and visuomotor skills, b) executive functions and working memory and c) impulsivity and decision-making.

Using a battery of neuropsychological tests tapping into the above domains ${ }^{69}$, we compared the performance of a group of patients following CNS-depressant medication overdose with that of a Control Group with non-CNS-depressant drug overdose at the point of discharge from the hospital-treated overdose episode. Given the broad range of acute cognitive deficits caused by therapeutic doses of CNS-depressants and 
the duration of action of a single dose, we hypothesized the CNS-Depressant Group would be impaired in all domains of cognition when compared to the Control Group. This was the first study that has examined subclinical impairment in a range of cognitive domains following clinical 'recovery' from CNS-Depressant drug overdose.

Our results showed that the CNS-Depressant Group was impaired in all tests in all three domains ${ }^{66}$. After adjusting for confounding factors CNS-Depressant Group was found to be impaired in visual attention and visuomotor skills, executive functions and working memory. They were also more impulsive in decision-making than the nonCNS-depressant group. Furthermore, planning task results indicated that the patients may perform normally in planning tasks with 2-3 steps but performance could fall behind at 4-5 step tasks. According to cognitive models of driving ${ }^{70,71}$, these cognitive functions are the main cognitive determinants of driving behaviour. The regression models for tests that tap into these domains suggest that drug effects could be equivalent to a 'cognitive aging' of these patients by $10-20$ years. This could be detrimental because the impairment is acute, and the patients do not have time to develop coping mechanisms as they do with normal ageing.

Basic assessment of patients for above cognitive deficits does not require sophisticated equipment. We have also used simple pen and paper tests available free of charge such as the Trail-Making Tests in our bedside cognitive assessments ${ }^{6,72}$. The TrailMaking Test-B has been widely applied in off-road evaluation of fitness-to-drive (Korner-Bitensky et al. 2006), and poor performance in this test (i.e. $<10^{\text {th }}$ percentile) is associated with poor driving performance $^{73}$ and increased risk of traffic accidents $^{74}$. In our sample of patients discharged after CNS-depressant overdose, performance of $63 \%$ of the subjects was below $10^{\text {th }}$ percentile.
Given that the patients leaving the hospital are left with a significant cognitive toxicity spanning multiple cognitive domains, are they more prone to real-life adverse events during the post discharge period?

To answer this question we took our research from bedside to roadside in our next study. Here we explored whether patients with psychotropic drug overdose are at a higher risk of a traffic accident in the period following discharge. This was a selfcontrolled case-series study which we did in the New South Wales, Australia ${ }^{75}$.

We conducted this study through datalinkage (i.e. by linking already collected data in two independent databases). The first database that we used was the NSW Admitted Patient Data Collection which records all hospital admission data including the diagnosis, the type of overdose, treatment etc. The second was the NSW Roads and Traffic Authority CrashLink dataset which records traffic accident data. Both these databases record some common information of a given individual, such as surname, first name, date of birth, sex, postcode etc. Using this common information we linked the two datasets, and identified whether a given individual who gets admitted after an overdose had been a driver involved in a traffic accident a) in the period following discharge from the hospital (i.e. exposed period) and b) the period before overdose (i.e. control period). By this method we made a retrospective cohort of 27087 patients who had 40845 hospital admissions following psychotropic drug overdose.

The characteristics of this cohort of patients were very similar to the sample of CNSDepressant Group in our clinical study. During the post-discharge period with in first 3 days following overdose, the patients were 3.5 times more prone to traffic accidents (Incidence rate ratio: 3.49 , 95\% CI: 1.66 , $7.33, p=0.001)$. To put this into context, this risk is equivalent to that of a blood alcohol level of $0.09 \mathrm{~g} / \mathrm{dL}$, which is well above the legal limit for driving. The risk diminished with time but remained elevated within the 
first week following overdose. These results can be explained by the drug effects. For instance, if the overdose is 16 times the defined daily dose (as we estimated in the clinical study), it will take 4 half-lives for the drug even to reach the therapeutic levels. The puzzle was the significant increase in the risk we observed during the 4 weeks. Even after adjusting for the initial increase in the incidence of accidents the accident risk remained elevated (Incidence rate ratio: $1.53,95 \%$ CI $1.16,2.02, p=0.003)$ in the subjects. Would this continuing risk be mirrored in their cognitive recovery?

Stewart Oxley - our doctoral student at the time - examined this in a follow up study ${ }^{72}$. He tested cognitive functions in a cohort of CNS-depressant overdosed patients and CNS-non-depressant overdosed patients on discharge, and 7 and 28 days following overdose. The pattern of cognitive recovery of the CNS-D group mirrored the pattern of reduction in traffic accident risk. In other words, their recovery was significantly slower for key neurocognitive domains underlying driving in complex traffic situations, namely, cognitive flexibility, cognitive efficiency, and working memory.

\section{What are the clinical and medicolegal implications of these findings?}

Although the evidence base was created largely in the Western counties, I believe the clinical implications of the findings are equally valid for Sri Lanka where the traffic conditions are more chaotic and the cognitive demands of driving are even greater.

Taking a brief history of driving behaviour would help to tailor the management of the outpatients who need to be treated with CNS-D medications. Benzodiazepine and opioid analgesic treatment has to be limited for short courses and more permanent methods have to be embarked on when treating insomnia, anxiety disorders and pain. Prescribing short-acting hypnotics for patients who drive motor vehicles or ride bicycles or operate machinery would minimize the morning-after effects. We saw alcohol and benzodiazepines having a potentiating effect to increase the risk of accidents. Therefore the patients on benzodiazepines should be warned not to take even small amounts of alcohol if they intend to drive a vehicle during rest of the day.

In cases of CNS-depressant overdose, keeping the patients longer in hospital may not be feasible given the increasing demand for hospital beds. Therefore, 'clinical recovery' may remain an acceptable criterion to discharge those patients, provided clear instructions are given on discharge. Whilst providing reassurance that the patients are 'fit to go home', we should warn patients that their cognitive functions may not have fully recovered and hence may affect their attention, memory, planning, social and financial decision making, driving and operating machinery etc.

We saw that driving during the first week following overdose is equivalent to drunk driving. In some countries the physician has the right to recommend the traffic authorities to temporarily withhold the driving licence of the patient in this situation. Since such medicolegal procedures take time in our setting, what we can do is to strongly advise the patients not to drive during this period. As the increased traffic accident risk remains significantly elevated even 1- 4 weeks after exposure, and due to the risk that they pose to the public, commercial vehicle drivers may have to avoid driving for more than one week. We should also take the above into account when determining the time that the patient should be away from their work, for instance, when issuing medical certificates for employed individuals.

Given the cognitive deficits demonstrated, some patients may not be able to remember the advice given verbally. This may be a particular problem in patients overdosed with benzodiazepines who are prone to anterograde amnesia ${ }^{76,77}$. Therefore it is preferable to give these instructions also in writing. 


\section{Assessment of Cognitive Functions in Clinical Contexts}

A recurring theme in the research is Advanced Assessment of Cognitive Functions in Clinical Contexts. Advanced cognitive assessment is not only limited to neurotoxicology. It has wider clinical applications in neurological and neuropsychiatric conditions:

1. To diagnose distinct cognitive disorders (e.g. different types of dementias and mild cognitive impairment),

2. To monitor response to treatment (e.g. dementia, ADHD) and cognitive rehabilitation (e.g. in post-stroke patients),

3. To trace the recovery and fitness to return to activities (e.g. post-concussion athletes),

4. To determine the strengths of the patient (i.e. spared cognitive functions) and

5. To rule out healthy individuals with subjective complaints.

In the countries where the resources are available, these assessments are an integral component of patient management. Although our health sector has reasonably advanced physical rehabilitation facilities, cognitive rehabilitation is poorly resourced area.

Our cognition research and clinical service functions are now conducted at two facilities: Clinical Neurophysiology Unit, Teaching Hospital, Peradeniya and the Clinical Neurophysiology and Cognitive Neurosciences Laboratory in the Department of Physiology of the Faculty of Medicine. We employ state-of-the-art neuropsychological and neurophysiological techniques to assess neurophysiological and cognitive deficits. We have two trained technical officers and one clinical research assistant.

Over last 4-years we have created normative datasets for a number of cognitive tests for Sri Lankan population. Based on regression models created from the data of nearly 400 individuals, we interpret our patient test results against age-, sex-, education- and IQadjusted norms, thus making them valid in the local context.

We commenced the Memory and Cognition Clinic at the Department in 2014 to perform advanced cognitive assessments. We started off getting occasional referrals from the Teaching Hospital Peradeniya. Two years down the line, we have now expanded our services other hospitals and gradually more referrals are coming in. I think we are making progress.

\section{Acknowledgements}

None of these would have been possible if not for the funding and support from a number of institutions and organisations. Especially, I would like to acknowledge my alma mater and my employer, University of Peradeniya for supporting my research. I thank The University of Newcastle, and The Endeavour Programme of the Australian Government for generously supporting my research since 2008. My pesticide research is funded by the Wellcome Trust, Australian National Health and Medical Research Council and the South Asian Clinical Toxicology Research Collaboration.

Ladies and gentlemen, The Greek essayist Plutarch once said, "Mind is not a vessel to be filled, but a fire to be kindled". I think that summarises what my mentors instilled in my mind. On that sentiment let me thank my mentors Prof. Nimal Senanayake, Prof. Vajira Weerasinghe, Dr. Udaya Dangahadeniya, Prof. Pat Michie, Prof. Alison Jones and Prof. Greg Carter. I would also like to thank my research collaborators, Professors Indika Gawarammana, Dr. Lakshman Karalliedde, Dr. Keethi Kularatne, Professors Andrew Dawson, Nick Buckley and Ian Whyte, and my postgraduate students Dr. Stewart Oxley and Dr. Chanaka Kahathuduwa. I also acknowledge the support of my colleagues at the Department of Physiology and the South Asian Clinical Toxicology Research Collaboration of the Faculty of Medicine Peradeniya, School of 
Psychology and Department of Clinical Pharmacology of the University of Newcastle. My research would not have been possible if not for the immense support and the tolerance of the staff of the toxicology units of the Teaching Hospital Peradeniya and Base Hospital Nuwara Eliya and the Calvary Mater Hospital Newcastle. I take this opportunity to acknowledge my teachers at the St. Anthony's college, Kandy for guiding me to clear numerous hurdles during my school days.

On this prestigious occasion I also must treasure the intellectual stimulation that my family provided me during my formative years. I thank my mother Mrs. Berney Dassanayake, my elder brothers Chinthaka and Jeevaka, and my elder sisters, Achala, Uthpala and Sithila. I thank my wife Deva for her love, encouragement, commitment and criticism during the last twenty years of my academic and research career.

I would like thank the President and the Council of the Kandy Society of Medicine again for bestowing me the honour of presenting my research during this prestigious inaugural ceremony. Ladies and gentlemen, finally I thank you for your patience in listening.

Let me conclude my oration with a quote by the Cuban-American Essayist, Anaïs Nin: "The possession of knowledge does not kill the sense of wonder and mystery. There is always more mystery."

\section{References:}

1. Dassanayake TL, Weerasinghe VS, Senanayake N. Cognitive processing time in a simple visual reaction time task. Proceedings of Physiological Society of Sri Lanka: Annual Sessions. Sri Lanka 2004:7.

2. Cognitive processing time in a simple visual reaction time task. Proceedings of the Peradeniya University Research Sessions; 2004.
3. Dassanayake T, Weerasinghe V, Dangahadeniya U, Kularatne K, Dawson A, Karalliedde L, Senanayake N. Cognitive processing of visual stimuli in patients with organophosphate insecticide poisoning. Neurology 2007;68:2027-30.

4. Kahathuduwa CN, Dassanayake TL, Amarakoon AM, Weerasinghe VS. Acute effects of theanine, caffeine and theanine-caffeine combination on attention. Nutritional Neuroscience 2016. Epub ahead of print. Doi:10.1080/1028415x.2016.1144845

5. Van der Hoek W, Konradsen F, Athukorala K, Wanigadewa T. Pesticide poisoning: a major health problem in Sri Lanka. Social Science and Medicine 1998;46(4-5):495-504. Doi:10.1016/S0277-9536(97)00193-7

6. Eddleston M. Patterns and problems of deliberate self-poisoning in the developing world. Quarterly Journal of Medicine 2000;93(11):715-31. Doi:10.1093/qjmed/93.11.715

7. Eddleston M, Phillips MR. Self poisoning with pesticides. British Medical Journal 2004;328(7430):42-4. Doi: $\underline{10.1136 / \mathrm{bmj} .328 .7430 .42}$

8. Senanayake N, Karalliedde L. Neurotoxic effects of organophosphorus insecticides. An intermediate syndrome. New England Journal of Medicine 1987;316(13):761-3. Doi:10.1056/NEJM198703263161301

9. Lotti M, Becker CE, Aminoff MJ. Organophosphate polyneuropathy: pathogenesis and prevention. Neurology 1984;34(5):658-62. Doi:10.1212/WNL.34.5.658

10. Abou-Donia MB. Organophosphorus ester-induced chronic neurotoxicity. Archives of Environmental Health 2003;58(8):484-97. Doi:10.3200/AEOH.58.8.484-497 
11. Dille JR, Smith PW. Central Nervous System Effects of Chronic Exposure to Organophosphate Insecticides. Aerospace Medicine 1964;35:474-8.

12. Gershon S, Shaw FH. Psychiatric sequelae of chronic exposure to organophosphorus insecticides. Lancet 1961;1(7191):1371-4.

Doi:10.1016/S0140-6736(61)92004-9

13. Metcalf DR, Holmes JH. EEG, psychological, and neurological alterations in humans with organophosphorus exposure. Annals of the New York Academy of Sciences 1969;160(1):357-65. Doi:10.1111/j.17496632.1969.tb15857.x

14. Durham WF, Wolfe HR, Quinby GE. Organophosphorus insecticides and mental alertness. Archives of Environmental Health 1965;10:55-66. Doi:10.1080/00039896.1965.1066395 3

15. Jamal GA. Neurological syndromes of organophosphorus compounds. Adverse Drug Reactions and Toxicological Reviews 1997;16(3):133-70.

16. Steenland K, Jenkins B, Ames RG, O'Malley M, Chrislip D, Russo J. Chronic neurological sequelae to organophosphate pesticide poisoning. American Journal of Public Health 1994;84(5):731-6.

Doi:10.2105/AJPH.84.5.731

17. Savage EP, Keefe TJ, Mounce LM, Heaton RK, Lewis JA, Burcar PJ. Chronic neurological sequelae of acute organophosphate pesticide poisoning. Archives of Environmental Health 1988;43(1):38-45.

Doi:10.1080/00039896.1988.9934372
18. Rosenstock L, Keifer M, Daniell WE, McConnell R, Claypoole K. Chronic central nervous system effects of acute organophosphate pesticide intoxication. The Pesticide Health Effects Study Group. Lancet 1991;338(8761):223-7. Doi:10.1016/0140-6736(91)90356-T

19. Wesseling C, Keifer M, Ahlbom A, McConnell R, Moon JD, Rosenstock L, Hogstedt C. Long-term neurobehavioral effects of mild poisonings with organophosphate and n-methyl carbamate pesticides among banana workers. International Journal of Occupatioanl and Environmental Health 2002;8(1):27-34. Doi:10.1179/oeh.2002.8.1.27

20. Fiedler N, Kipen H, Kelly-McNeil K, Fenske R. Long-term use of organophosphates and neuropsychological performance. American Journal of Industrial Medicine 1997;32(5):487-96. Doi:10.1002/ (SICI)10970274(199711)32:5<487::AIDAJIM8>3.0.CO;2-P

21. Stallones L, Beseler C. Pesticide illness, farm practices, and neurological symptoms among farm residents in Colorado. Environmental Research 2002;90(2):89-97.

Doi:10.1006/enrs.2002.4398

22. London L, Myers JE, Nell V, Taylor T, Thompson ML. An investigation into neurologic and neurobehavioral effects of long- term agrichemical use among deciduous fruit farm workers in the Western Cape, South Africa. Environmental Research 1997;73 (1-2): 132-45. Doi:10.1006/enrs.1997.3715 
23. Daniell W, Barnhart S, Demers $P$, Costa LG, Eaton DL, Miller M, Rosenstock L. Neuropsychological performance among agricultural pesticide applicators. Environmental Research 1992;59(1):217-28. Doi:10.1016/S0013-9351(05)80241-5

24. Stephens R, Spurgeon A, Calvert IA, Beach J, Levy LS, Berry H, Harrington JM. Neuropsychological effects of long-term exposure to organophosphates in sheep dip. Lancet 1995;345(8958):1135-9.

Doi:10.1016/S0140-6736(95)90976-1

25. Steenland K, Dick RB, Howell RJ, Chrislip DW, Hines CJ, Reid TM, Lehman E, Laber P, Krieg EF, Jr., Knott C. Neurologic function among termiticide applicators exposed to chlorpyrifos. Environmental Health Perspectives 2000;108(4):293-300.

26. Chen Y. Organophosphate-induced brain damage: Mechanisms, neuropsychiatric and neurological consequences, and potential therapeutic strategies. NeuroToxicology 2012;33(3):391-400. Doi:10.1016/j.neuro.2012.03.011.

27. Dassanayake T, Weerasinghe V, Dangahadeniya U, Kularatne K, Dawson A, Karalliedde L, Senanayake N. Long-lasting effects of acute organophosphorus insecticide poisoning on cognitive processing of visual information. Journal of Medical Toxicology 2008;4(3):209.

28. Dassanayake T, Weerasinghe V, Dangahadeniya U, Kularatne K, Dawson A, Karalliedde L, Senanayake N. Effects of organophosphate pesticide poisoning on time-course of cognitive processing. Clinical Toxicology 2006;44(4):429-30.
29. Dassanayake T, Weerasinghe V, Dangahadeniya U, Kularatne K, Dawson A, Karalliedde L, Senanayake N. Long-term event-related potential changes following organophosphorus insecticide poisoning. Clin Neurophysiol 2008;119(1):144-50. Doi:10.1016/ j.clinph.2007.09.134

30. Rugg MD, Coles MGH.

Electrophysiology of Mind: Eventrelated Brain Potentials and Cognition: Oxford University Press, 1995.

31. Kutas M, McCarthy G, Donchin E. Augmenting mental chronometry: the P300 as a measure of stimulus evaluation time. Science 1977; 197:79295. JSTOR, www.jstor.org/stable/1744874.

32. McCarthy G, Donchin E. A metric for thought: A comparison of P300 latency and reaction time. Science 1981;211:77-80. JSTOR, www.jstor.org/stable/1685542.

33. Petras JM. Soman neurotoxicity. Fundamental and Applied Toxicology 1981;1(2):242.

34. Veronesi B, Jones K, Pope C. The neurotoxicity of subchronic acetylcholinesterase (AChE) inhibition in rat hippocampus. Toxicology and Applied Pharmacology 1990; 104(3):440-56. Doi:10.1016/0041008X(90)90166-R

35. Dassanayake T, Gawarammana I, Weerasinghe V, Dissanayake P, Pragaash S, Dawson A, Senanayake N. Auditory event-related potential changes in chronic occupational exposure to organophosphate pesticides. Clinical Neurophysiology 2009;120(9):1693-98. Doi:10.1016/j.clinph.2009.07.034. 
36. Dassanayake T, Gawarammana I, Weerasinghe V, Dissanayake S, Pragaash S, Dawson A, Senanayake N. Cognitive impairment in chronic occupational exposure to organophosphates:

Psychophysiological evidence. Clinical Toxicology 2008;46(7):231.

37. Neurophysiological markers of Cognitive Impairment in Organophosphate and Carbamate Insecticide Poisoning: Preliminary Findings. 4th Biennial Conference of South Asian Association of Physiologists (SAAP-3) 2014; Dhaka, Bangladesh.

38. Australian Government Department of Health and Ageing. Australian statistics on medicines 2007. Canberra 2009.

39. Hudson TJ, Edlund MJ, Steffick DE, Tripathi SP, Sullivan MD. Epidemiology of Regular Prescribed Opioid Use: Results from a National, Population-Based Survey. Journal of Pain and Symptom Management 2008;36(3):280-88.

Doi:10.1016/j.jpainsymman.2007.10.0 03 .

40. Manchikanti L, Singh A. Therapeutic opioids: A ten-year perspective on the complexities and complications of the escalating use, abuse, and nonmedical use of opioids. Pain Physician 2008;11(SPEC. ISS. 2).

41. Parsells Kelly J, Cook SF, Kaufman DW, Anderson T, Rosenberg L, Mitchell AA. Prevalence and characteristics of opioid use in the US adult population. Pain 2008;138(3):507-13. Doi:10.1016/j.pain.2008.01.027.
42. Demland JA, Jing Y, Kelton CML, Guo JJ, Li H, Wigle PR. Use pattern and off-label use of atypical antipsychotics in bipolar disorder 1998-2002. American Health and Drug Benefits 2009;2(4):184-91.

43. Diatta T, Blazejewski S, Portier A, Lignot S, Quesnot A, Moore N, Fourrier-Reglat A. Patterns and frequency of atypical antipsychotic prescribing in psychiatric medical centers: A cross-sectional national survey. Fundamental and Clinical Pharmacology 2007;21(4):371-78. Doi:10.1111/j.1472-8206.2007.00492.x

44. Mattila M. Acute and subacute effects of diazepam on human performance:

Comparison of plain tablet and controlled release capsule. Pharmacology and Toxicology 1988;63(5):369-74.

Doi:10.1111/j.16000773.1988.tb00970.x

45. Mattila MJ, Vanakoski J, Kalska H, Seppala T. Effects of alcohol, zolpidem, and some other sedatives and hypnotics on human performance and memory. Pharmacology Biochemistry and Behavior 1998;59(4):917-23. Doi:10.1016/S0091-3057(97)00506-6

46. Amado-Boccara I, Gougoulis N, Poirier Littre MF, Galinowski A, Loo H. Effects of antidepressants on cognitive functions: a review. Neuroscince and Behavioral Reviews 1995;19(3):479-93.

47. Zacny JP. A review of the effects of opioids on psychomotor and cognitive functioning in humans. Experimental and Clinical Psychopharmacology 1995;3(4):432-66. 
48. Patat A, Klein MJ, Hucher M. Effects of single oral doses of clobazam, diazepam and lorazepam on performance tasks and memory. European Journal of Clinical Pharmacology 1987;32(5): 461-66. Doi:10.1007/BF00637670

49. Seppala K, Korttila K, Hakkinen S, Linnoila M. Residual effects and skills related to driving after a single oral administration of diazepam, medazepam or lorazepam. British Journal of Clinical Pharmacology 1976;3(5):831-41. Doi:10.1111/ j.1365-2125.1976.tb00635.x

50. Rothenberg S, Schottenfeld S, Meyer RE. Performance differences between addicts and non addicts.

Psychopharmacology 1977;52(3):299306. Doi:10.1007/BF00426715

51. Beuzen JN, Taylor N, Wesnes K, Wood A. A comparison of the effects of olanzapine, haloperidol and placebo on cognitive and psychomotor functions in healthy elderly volunteers. Journal of Psychopharmacology 1999;13(2):152-58. Doi:10.1177/ 026988119901300207

52. Coull JT, Middleton HC, Robbins TW, Sahakian BJ. Clonidine and diazepam have differential effects on tests of attention and learning.

Psychopharmacology 1995;120(3):322-32.

Doi:10.1007/BF02311180

53. Coull JT, Middleton HC, Robbins TW, Sahakian BJ. Contrasting effects of clonidine and diazepam on tests of working memory and planning.

Psychopharmacology 1995;120(3):311-21. Doi:10.1007/BF02311179

54. Meador KJ, Gevins A, Leese PT, Otoul C, Loring DW. Neurocognitive effects of brivaracetam, levetiracetam, and lorazepam. Epilepsia 2011;52(2):26472. Doi:10.1111/j.15281167.2010.02746.x. Epub 2010 Sep 30.
55. Deakin JB, Aitken MR, Dowson JH, Robbins TW, Sahakian BJ. Diazepam produces disinhibitory cognitive effects in male volunteers. Psychopharmacology 2004;173(1-2): 88-97. Doi:10.1007/s00213-003-1695-4

56. Dassanayake T, Michie P, Carter G, Jones A. Effects of benzodiazepines, antidepressants and opioids on driving: A systematic review and meta-analysis of epidemiological and experimental evidence. Drug Safety 2011;34(2):12556. Doi:10.2165/11539050-00000000000000 .

57. Barbone F, McMahon AD, Davey PG, Morris AD, Reid IC, McDevitt DG, MacDonald TM. Association of roadtraffic accidents with benzodiazepine use. Lancet 1998;352(9137):1331-36. Doi:10.1016/S0140-6736(98)04087-2

58. Engeland A, Skurtveit S, Morland J. Risk of road traffic accidents associated with the prescription of drugs: a registry-based cohort study. Annals of Epidemiology 2007;17(8):597-602. Doi:10.1016/j.annepidem.2007.03.009

59. Bramness JG, Skurtveit S, Neutel CI, Morland J, Engeland A. Minor increase in risk of road traffic accidents after prescriptions of antidepressants: A study of population registry data in Norway. Journal of Clinical Psychiatry 2008;69(7):1099-103.

60. Rapoport MJ, Lanctot KL, Streiner DL, Bedard M, Vingilis E, Murray B, Schaffer A, Shulman KI, Herrmann N. Benzodiazepine use and driving: A meta-analysis. Journal of Clinical Psychiatry 2009;70(5):663-73. Doi: $10.4088 / \mathrm{JCP} .08 \mathrm{~m} 04325$.

61. Menefee LA, Frank ED, Crerand C, Jalali S, Park J, Sanschagrin K, Besser $M$. The effects of transdermal fentanyl on driving, cognitive performance, and balance in patients with chronic nonmalignant pain conditions. Pain Medicine 2004;5(1):42-49. doi/10.1111/j.1526-4637.2004.04005 
62. Wingen $\mathrm{M}$, Bothmer J, Langer S, Ramaekers JG. Actual driving performance and psychomotor function in healthy subjects after acute and subchronic treatment with escitalopram, mirtazapine, and placebo: a crossover trial. Journal of Clinical Psychiatry 2005;66(4):436-43.

63. Coben JH, Davis SM, Furbee PM, Sikora RD, Tillotson RD, Bossarte RM. Hospitalizations for Poisoning by Prescription Opioids, Sedatives, and Tranquilizers. American Journal of Preventive Medicine 2010;38(5):51724.

Doi:10.1016/j.amepre.2010.01.022.

64. National Institute of Health. Hospital episode statistics: inpatient data by external cause 2009-10. http://www.hesonline.nhs.uk/Ease/serv let/ContentServer?siteID=1937\&categ oryID $=211$ (Accessed: 08/06/2011), 2011.

65. Australian Institute of Health and Welfare National Hospital Morbidity Database. Separation, patient day and average length of stay statistics by principal diagnosis in ICD-10-AM, Australia, 1998-99 to 2007-08. http://www.aihw.gov.au/hospitals-datacube/?id=6442475319 (last accessed: 09/06/2011), 2011.

66. Dassanayake TL, Michie PT, Jones A, Carter G, Mallard T, Whyte I. Cognitive impairment in patients clinically recovered from central nervous system depressant drug overdose. Journal of Clinical Psychopharmacology 2012;32(4):50310.

Doi:10.1097/JCP.0b013e31825d6ddb.

67. Dassanayake WDMTL. Effects of central nervous system depressant drug overdose on cognitive functions and driving. The University of Newcastle, 2012. http://hdl.handle.net/

$1959.13 / 932260$
68. Dassanayake TL, Michie PT, Jones AL, Mallard T, Whyte IM, Carter GL. Cognitive skills underlying driving in patients discharged following selfpoisoning with central nervous system depressant drugs. Traffic Injury Prevention 2012;13(5):450-7. Doi:10.1080/15389588.2012.671983.

69. CANTABeclipse version 3: Test administration guide [program]: Cambridge Cognition Ltd., 2006.

70. Michon JA. A critical view of driver behavior models: What do we know, what should we do? In: Evans L, Schwing RC, editors. Human behavior and traffic safety. New York: Plenum Press, 1985:485-520. Doi:10.1007/9781-4613-2173-6_19

71. Ranney TA. Models of driving behavior: a review of their evolution. Accident Analysis \& Prevention 1994;26(6):733-50. Doi:10.1016/00014575(94)90051-5

72. Oxley SO, Dassanayake TL, Carter GL, Whyte I, Jones AL, Cooper G, Michie PT. Neurocognitive Recovery After Hospital-Treated Deliberate SelfPoisoning With Central Nervous System Depressant Drugs: A Longitudinal Cohort Study. Journal of Clinical Psychopharmacology 2015;35(6):1-9.

Doi:10.1097/JCP.0000000000000417.

73. Classen S, Horgas A, Awadzi K, Messinger-Rapport B, Shechtman O, Joo Y. Clinical predictors of older driver performance on a standardized road test. Traffic Injury Prevention 2008;9(5):456-62. Doi:10.1080/15389580802260026.

74. Stutts JC, Stewart JR, Martell C. Cognitive test performance and crash risk in an older driver population. Accident Analysis \& Prevention 1998;30(3):337-46. Doi:10.1016/S0001-4575(97)00108-5 
75. Dassanayake TL, Jones AL, Michie PT, Carter GL, McElduff P, Stokes BJ, Whyte IM. Risk of Road Traffic Accidents in Patients Discharged Following Treatment for Psychotropic Drug Overdose: A Self-Controlled Case Series Study in Australia. CNS Drugs 2012;26(3):269-76.

Doi:10.2165/11599790-00000000000000

76. Verwey B, Eling P, Wientjes H, Zitman FG. Memory impairment in those who attempted suicide by benzodiazepine overdose. Journal of Clinical Psychiatry 2000;61(6):456-59.
77. Verwey B, Muntendam A, Ensing K, Essink G, Pasker-de Jong PC, Willekens FL, Zitman FG. Clinically relevant anterograde amnesia and its relationship with blood levels of benzodiazepines in suicide attempters who took an overdose. Progress in Neuro-Psychopharmacology \& Biological Psychiatry 2005;29(1):4753. Doi:10.1016/j.pnpbp.2004.10.004 